\title{
ИНТЕРСЕМИОТИЧЕСКИЕ ОТНОШЕНИЯ В ПЕРЕВОДЕ КУЛЬТУРНОГО ИНОГО (НА ПРИМЕРЕ ФИЛЬМА НОСТАЛЬГИЯ АНДРЕЯ ТАРКОВСКОГО)
}

\author{
INTERSEMIOTIC RELATIONS IN TRANSLATING CULTURAL OTHERNESS \\ (BASED ON THE EXAMPLE OF ANDREI TARKOVSKY'S NOSTALGIA)
}

\author{
MARIA MOCARZ-KLEINDIENST
}

\begin{abstract}
AвSTRACT. The title nostalgia in Andrei Tarkovsky's film is evoked by the Russian writer's longing for his family and homeland. It is activated in his contact with another culture, in this case with Italian culture. This paper attempts to provide an analysis of the mechanisms used by the director to make a projection of this emotional state and to portray it in the film. A number of intersemiotic relations among visual, verbal and sound codes were analysed. The following relations were identified: complementarity, parallelism and contradiction. The provided examples show the significance of the visual code as an indicator of cultural otherness. They also prove the diversity of stylistic devices used for transposing emotional states to the physical world.
\end{abstract}

Keywords: linguistic humour, neologisms, linguistic games, intertextual references

Maria Mocarz-Kleindienst, Katolicki Uniwersytet Lubelski Jana Pawła II, Lublin - Polska, momar@kul.pl

ORCID ID: 0000-0002-2205-5470

Ностальгия, одна из самых известных кинокартин Андрея Тарковского, была снята в 1983 году в Италии. Сюжетная линия фильма связывает две страны: Россию и Италию. Сосуществование двух миров - это один из принципов, организующих кино Тарковского. Главный герой фильма - русский писатель, профессор истории Андрей Горчаков (в этой роли снимается Олег Янковский) приезжает в Италию с целью изучить биографию известного композитора XVIII века Павла Сосновского. Прообразом Сосновского послужил Максим Березовский, украинский композитор, певец, дирижер, музыку которого использовал режиссер в своем фильме. Горчаков путешествует по Тоскане вместе с итальянской переводчицей Эудженией. Профессор скучает по родине, собирается вернуться в Россию, однако некоторые обстоятельства мешают ему скоро увидеть родину. У него возникают проблемы со здоровьем, и ему приходится лечь на курс реабилитации в местную водолечебницу, по- 
строенную в честь Екатерины Сиенской. Там Андрей знакомится с учителем математики Доменико, которого все вокруг считают мистическим фанатиком, державшим свою семью дома взаперти семь лет, пытаясь таким образом спасти ее от приближающегося конца света. Сумасшедшего Доменико терзает назойливая мысль - пройти с зажженной свечой через бассейн, чтобы спасти мир. Оба героя - Горчаков и Доменико сближаются от овладевшего ими чувства непонимания и отчуждения со стороны окружающих. И именно Доменико просит Горчакова самому пройти с зажженной свечой через минеральный источник с целью спасти человечество, а он сам совершает самосожжение. Русскому профессору этот подвиг наконец удается.

Само путешествие в Италию означает для Горчакова встречу с другой культурой и одновременно разлуку с родиной и близкими ему людьми. Чем дольше продолжается путешествие по Италии, тем сильнее проявляется у него тоска по родине. То, что вначале должно было по-настоящему восхитить профессора (например, памятники искусства), во время поездки становится барьером, который ему трудно преодолеть. Жизненная ситуация, в которой он оказался, вызывает чувство ностальгии. Понятие это ассоциируется с утраченным миром, пространством, ведь ностальгия происходит от греческого nostos (возвращение на родину) и algos (страдание), отсюда буквальное значение - тоска по родным местам. Как замечает Альберто Моравиа, ностальгия, о которой идет речь в одноименном фильме Андрея Тарковского, это состояние души, хорошо известное путешественникам и называющееся по-английски приблизительно „home sickness”, то есть недомогание от разлуки с домом [Моравиа 2016: 9]. По словам самого Тарковского, „название фильма «Ностальгия» означает тоску по тому, что так далеко от нас, по тем мирам, которые нельзя объединить, но это также и тоска по нашему родному дому, по нашей духовной принадлежности" [O nрuроде ностальгии].

Непосредственной причиной, вызывающей чувство ностальгии главного героя, считается его контакт с иной культурой. Столкновение двух понятийных категорий свое - чужое приводит к культурно и ментально обусловенной категории иного, понимаемой некоторыми учеными как так называемое третье пространство [см. Engel, Lewicki 2005]. Категория иного возникает там, где появляется ключевое слово «граница», разделяющее то, что нам хорошо знакомо и привычно, от того, что не укладывается в рамки наших образов, мыслей, убеждений. Пространство иного создают следующие факторы: объекты материальной и духовной культуры, обычаи, религия, искусство, менталитет, предметы повседневного обихода. 
Ностальгия как психическое состояние, затрагивающее эмоциональную сторону жизни человека, порождает вопрос: при помощи каких киноприемов режиссеру удается проецировать на экран это состояние, чтобы оно воспринималось зрителями как психическое недомогание. Тарковский использует два основных, доступных режиссеру кода: визуальный и вербальный, иногда и звуковой в виде фоновой музыки к фильму. В пространстве любого фильма как поликодового культурного явления обнаруживаются интерсемиотические отношения, развивающие его сюжетную линию.

Тема интерсемиотических отношений очень сложна в силу разнообразия контактов, устанавливаемых между разными знаковами системами. Вместе с тем она представляет собой малоисследованную область современного кинодискурса. В дальнейшей части анализа я сосредоточусь на избранных примерах интерсемиотических отношений в фильме Тарковского, в которых передаются реалии, архитектура, менталитет иной, то есть итальянской культуры. Частично я использую концепцию профессора Тересы Томашкевич, положившей основы для разработки этой темы. Выделенные ученым отношения - это эквивалентность, параллелизм, комплементарность, интерпретация и противоречие [Тоmaszkiewicz 2010: 33-44]. Интерсемиотический анализ любого фильма показывает, что этих типов слишком мало для того, чтобы, пользуясь только ими, составить разносторонний анализ отношений изображение - слово - звук. Поэтому в настоящем исследовании предпринимается попытка добавить другие типы отношений, возникающих в поликодовом пространстве фильма.

В общем, в основу предлагаемой мною концепции интерсемиотических отношений легли два критерия: временной и содержательный. Первый учитывает два плана: синхронный и последовательный (по аналогии с типами устного перевода), второй - смыслы, возникшие в результате сопоставления и взаимодействия знаковых систем (как в синхронном, так и последовательном планах) и представляющие собой единое целое, не сводимое к сумме его отдельных компонентов. При этом исхожу из предпосылки, что первичной, то есть самой главной семиотической системой в современном кинематографе является визуальный код - изображение, и именно ему подчиняется вербальный код. Такая точка зрения считается сходной с концепцией Веры Горшковой, утверждающей, что смысловая завершенность вербального компонента художественного фильма обеспечивается аудиовизуальным (звукозрительным) рядом в общем дискурсе фильма [Горшкова 2006: 77]. Сам Тарковский подчеркивал, что он выражает себя при помощи метафор. Кинокартина не символизирует жизнь, она ее выражает, отображает, отражая ее 
уникальность и неповторимость [Kulisiewicz]. На самом деле, в фильмах Тарковского, в том числе в Ностальгии, зрителю предоставляется возможность сосредоточиться на длящихся даже 3-5 минут кинокадрах, в которых отсутствуют слова. Так, в самом начале фильма зритель знакомится с тосканским ландшафтом [см. Citko 2013: 261], лишь через три минуты на его фоне появляется черная машина с главными героями. Первой мы видим выходящую из нее переводчицу, которая пытается убедить своего спутника Горчакова в исключительности посещаемого ими тосканского места, произнося следующие слова:

[03: 55] - Ты посмотришь, здесь удивительно. Когда я впервые ее увидела, я просто заплакала. [03:57 $]^{1}$

[04:02] - А этот свет напоминает мне осенние сумерки в Москве и Скучный сад. [04:04]

В приведенном высказывании Эуджении обнаруживаем первое из интерсемиотических отношений - комплементарность, т.е. взаимодополнение компонентов, принадлежащих разным знаковым системам: вербальной и визуальной. Героиня, находясь на фоне исключительного, по ее мнению, ландшафта, использует дейктические слова (здесь, этот), относящиеся прямо к тому, что изображено в кадре. Перед глазами Горчакова открывается красота пейзажа Италии. Женщина, отдавая себе отчет в том, что он принципиально отличается от ландшафта России, приостановившись в месте, где сквозь тучи медленно пробивалось солнце, определяет его коротким словом этот и сравнивает с сумерками в Москве, что ближе восприятию Горчакова. Таким образом, она помогает самому Горчакову и вместе с тем зрителям заметить неповторимость посещаемого места на основании их собственных ощущений.

Комплементарную связь изображения с вербальным кодом обнаруживает также следующий пример, в котором Доменико в ответ на поставленный женщиной вопрос показывает пальцем в небо.

[37: 33] - Никогда не забывайте того, что он сказал.

- Кто это он?

- А она?

- Святая Екатерина. [37: 56]

Жест в виде поднятого к небу (Богу) пальца является ответом на вопрос переводчицы „Кто это он?”. Только при условии одновременного вос-

${ }^{1}$ В каждом примере приводятся в квадратных скобках таймкоды, то есть данные о времени, когда синхронно передается изображение и вербальная информация. Таймкоды даются по электронному ресурсу: https:/ / www.youtube.com (доступ 10.08.2017). 
приятия звуковой и визуальной информации приведенное высказывание считается понятным.

Невозможность пересечь культурные границы - фактор, который обуславливает появление категории иного. Вскоре после своего приезда в Италию Горчаков начал осознавать, что если человек раньше не был полностью погружен в пространство данной культуры, то нельзя просто стать переводчиком этой культуры. Невозможно понять менталитет людей, воспитанных в данном культурном пространстве и пересечь культурные границы иного мышления, мировоззрения, воспитания. Именно такой смысл содержится в сцене в гостинице, в которой остановились путешествующие по Италии герои. Ниже приводится диалог между Эудженией и Горчаковым:

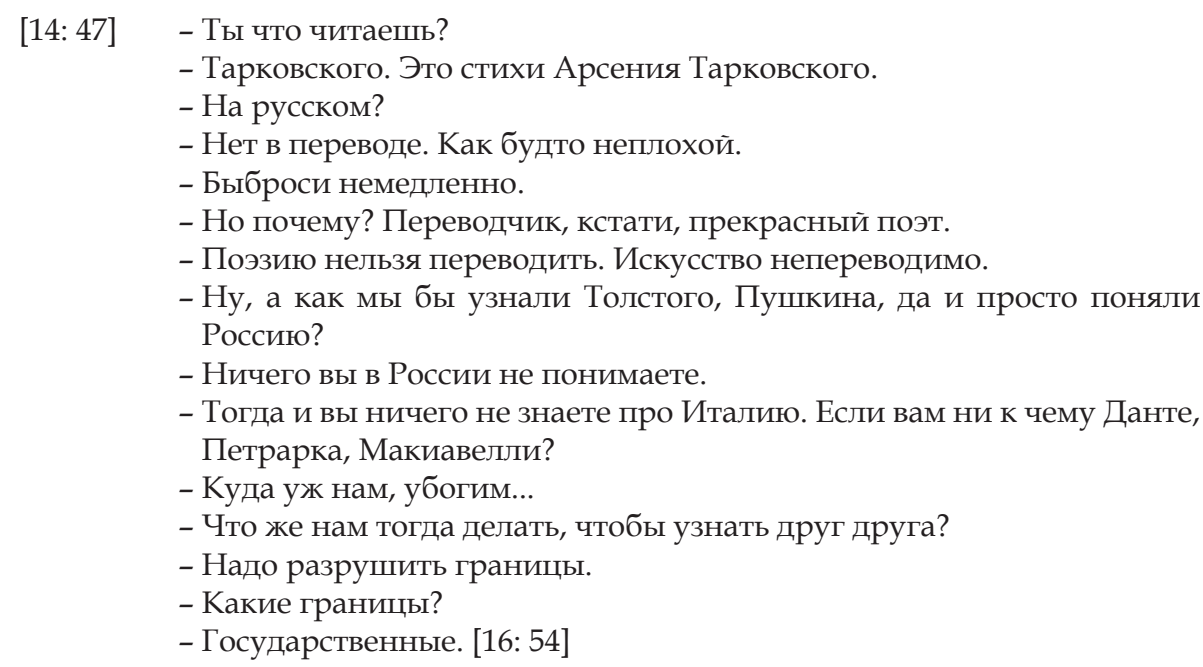

Герои ведут разговор о возможности или, скорее всего, невозможности понимать друг друга, познать другую культуру при помощи перевода. Их мнения расходятся. На протяжении всего диалога мы видим только их лица, застывшие взгляды, говорящие о непонимании друг друга. Горчаков поворачивает голову в другую сторону, подчеркивая таким жестом влияние некоторой границы между ними. Интересно также отметить, что силуэты Горчакова и переводчицы не встречаются в одном кадре, они разделены его границей. Диалог, который ведут герои, выполняет функцию параллелизма по отношению к их же собственным позам. Граница, существующая между героями, нанесенная границей кадра, передается параллельно в вербальном плане при помощи высказывания, в котором идет речь о государственных границах. Следуя принятым критериям, в данном случае можно заметить синхронный по- 
рядок наблюдаемых смыслов, возникающих вследствие интерактивных отношений между обеими знаковыми системами.

Присутствие параллелизма как смысла, полученного в результате сосуществования изображения и слова, всегда сопровождается синхронной передачей информации с использованием обоих кодов. Это означает, что обе семиотические системы появляются в одно и то же время и при помощи доступных им знаков передают ту же информацию, нередко приводя таким образом к так называемой редундатности (избыточности) высказывания. В качестве примера приведем следующую реплику:

[34: 50] - Сеньорита, извините, я вообще-то не курю. Вы не одолжите мне сигаретку?

- Ну, конечно, уж если вы не курите. [35: 38]

Доменико обращается с просьбой к переводчице Эуджении одолжить ему сигарету. Использует при этом типичное для итальянского речевого этикета обращение в женщинам: сенъорита. Обращение к женщине-итальянке по-итальянски вызывает некоторую редундатность высказывания. Однако если рассматривать целенаправленность такого приема с точки зрения культурных характеристик, то произнесенное слово является показателем культурного иного: русскоязычный зритель получает представление о типичной формуле обращения на итальянском языке.

Отношения параллелизма, из-за их довольно высокой частотности употребления, могут внутренне дифференцироваться. Судя по объему информации, передаваемой визуальными и вербальными средствами, можно выделить два типа: полный и частичный параллелизм. Ниже следует пример второго типа:

[54: 50] Вина выпьешь? [54: 59]

В заброшенном доме Доменико встречается с Горчаковым, угощает своего гостя хлебом и вином. Кадр показывает протянутую руку Доменико, держащую хлеб и рюмку вина. Почти в то же время слышится голос Доменико, спрашивающего Горчакова, хочет ли он напиться вина. Таким образом наблюдаемый в этой сцене частичный параллелизм касается слова Вино и его визуального представления. Второй элемент хлеб не получает своего вербального репрезентанта в переводной версии фильма. Частичный параллелизм замечается в аудиовизуальном произведении намного чаще, чем полный. Это объясняется пространственно-временными ограничениями кинопроизводства и поликодовым 
характером фильмов, в которых фрагментарность вербального текста компенсируется визуальным рядом. В фильме Тарковского, о чем упоминалось выше, сила воздействия на зрителя при помощи видеоряда сильнее вербального. Действие Ностальгии развивается в замедленном темпе, что позволяет зрителю лучше сосредоточиться на видеоизображении. Такое положение вещей помогает заметить и понять отношения, возникающие между вербальным текстом и визуальным рядом в последовательном порядке. Именно такой порядок пополнения визуального представления культурного иного при помощи вербальной информации наблюдается в следующей сцене:

[14: 05] Нет, не понимаю я тебя. Ты мне все уши прожужжал рассказами о Мадонне дель Парто. Мы проехали пол-Италии... Вся эта дорога, туман... Почему ты даже не зашел в церковь взглянуть на нее? [14: 20]

Данное высказывание выстраивает порядок последовательности по отношению к кадру, который мы видели несколькими минутами ранее в храме, где стоящие на коленях молодые женщины молились о ниспослании ребенка у иконы Мадонны. Всю эту сцену наблюдает одна Эуджения, стоя где-то у колонны. Горчаков отказался от посещения церковного интерьера тосканского храма. Информацию о том, что находящиеся в храме женщины просят Мадонну дель Парто Пьеро делла Франческа о даровании ребенка, зритель получает в дальнейшей части фильма. Таким образом эта часть диалога героев становится вербальной интерпретацией того изображения, с которым зритель познакомился несколько минут назад. Приведенный пример обнаруживает интерсемиотические отношения и другого типа, так как разговор сопровождается новым визуальным представлением: Горчаков, будучи адресатом поставленного вопроса, обходит его молчанием. Такая реакция порождает противоречие: присутствие на экране обоих героев и формула вопроса предопределяют диалогическую форму контакта. Эуджения своим пристальным взглядом ожидает вербальной реакции со стороны писателя. Однако Горчаков, погруженный в себя, сильно ощущая культурные различия и невозможность вербально оправдать свое поведение, молчит. Сам Тарковский в одном из данных им интервью так объясняет поведение своего героя:

Горчаков - профессор истории с мировой известностью. Как знаток истории итальянской архитектуры, он впервые получил возможность увидеть и дотронуться до тех памятников и зданий, с которыми до этого был знаком только по репродукциям и фотографиям. Вскоре после своего приезда в Италию он начал осознавать, что нельзя быть только посредником, переводчиком или знатоком произведений искусства, если ты сам не являешься частью этой культуры, из которой они и возникли [О природе ностальгии]. 
Следующий пример смысловых интерсемиотических отношений интерпретацию в последовательном порядке мы наблюдаем в случае других кодов, составляющих сюжет фильма: звука (в виде звучащей музыки) и вербального высказывания:

[51: 03] Ты слышал? Это Бетховен. [51: 03]

Сначала в фильме звучит Девятая симфония Бетховена, затем Доменико объясняет Горчакову, чью музыку они слушали. Следовательно, при помощи вербального высказывания поясняется звучавшая раньше музыка.

Вышеприведенные примеры интерсемиотических отношений в фильме Ностальгия показывают силу и значимость, с одной стороны, визуального кода как достоверного показателя другой культуры - итальянской, ее материальных и духовных показателей, с другой - обнаруживают богатство изобразительных возможностей транспозиции того, что свойственно внутреннему, душевному миру героев, в мир физических ощущений и наблюдений. Несомненно, они усиливают познавательную функцию культурного иного с точки зрения восприятия содержания фильма зрителями. Осознание типов интерсемиотических отношений, возникающих в пространстве фильма, позволяет лучше познать культуру, частью которой является данный фильм. Представленные интерсемиотические связи способствуют дифференциации культурного иного с точки зрения субъектов как представителей разных культур. Разнообразие взаимоотношений склоняет также к сосредоточенному наблюдению за деталями, активным поискам смыслов, скрытых в цепи произносимых слов. Для переводчика существование таких отношений обозначает необходимость учитывать все семиотические коды, существующие в фильме, хотя он работает только с одним - вербальным. К тому же стоит обратить особое внимание на временной порядок следования очередных отношений. Присутствие последовательного порядка взаимосвязей между изображением и словом в кинокартине вынуждает переводчика, прежде чем приступить к переводу, тщательно познакомиться с содержанием всего фильма. В этом заключалась суть привлечения в качестве иллюстративного материала переводной (русской) версии фильма.

\section{Библиография}

Горшкова В. Е. 2006. Перевод в кино, Иркутск: Иркутский государственный лингвистический университет.

Моравиа А. 2016. Великие о Великом, [в:] Я. Ярополов (сост.), Андрей Тарковский, Сталкер мирового кино, Москва: Алгоритм. 
О природе ностальгии. Интервью с Андреем Тарковским вел Гидеон Бахман, электронный pecyрс: http:/ / tarkovskiy.su/ texty/Tarkovskiy/Bachmann.html (доступ 5.09.2017).

Citko K. 2013. Wyobraźnia oniryczna. Obrazy w twórczości Andrieja Tarkowskiego, [в:] I. A. NDiaye, M. Sokołowski (ред.), Strefa filmu. Kino Andrieja Tarkowskiego, Toruń: Wydawnictwo Adam Marszałek.

Engel Ch., Lewicki R. (ред.) 2005. Interkulturalität. Slawistische Fallstudien, Innsbruck: Verlag der Sprachwissenschaft.

Kulisiewicz M., Ocalić petnię. Interpretacja filmów Tarkowskiego, электронный ресурс: www. jungpoland.org/pl/zbior-tekstow/ocalic-pelnie-interpretacja-filmow-tarkowskiego. html (доступ 8.09.2017).

Tomaszkiewicz T. 2006. Przekład audiowizualny, Warszawa: PWN.

Tomaszkiewicz T. 2010. Przekład audiowizualny, werbo-wizualny czy intersemiotyczny: różne wymiary tej samej rzeczywistości, „Lingwistyka Stosowana”, № 3. 
